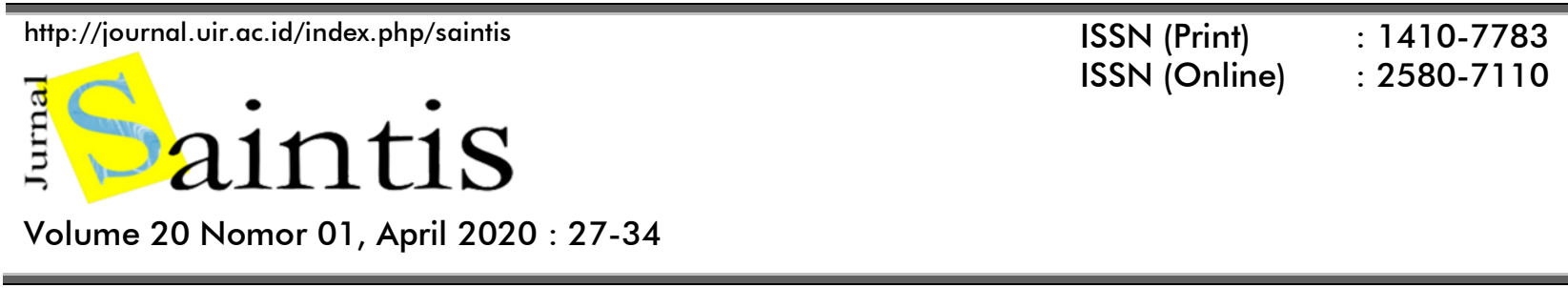

\title{
Analisis Implementasi Kawasan Teknopolitan di Kabupaten Pelalawan, Provinsi Riau
}

\author{
The Analysis of Techno Park Implementation in Pelalawan Regency, Riau Province
}

\author{
Afni M Yulandra ${ }^{1}$, Rona Muliana ${ }^{1, *}$, Firdaus $^{1}$ \\ ${ }^{1}$ Perencanaan Wilayah dan Kota, Universitas Islam Riau, Jalan Kaharuddin Nasution No.113, Pekanbaru, Indonesia
}

\begin{abstract}
*Penulis korespondensi : ronamuliana@eng.uir.ac.id
Tel.: +62-81-261-51-0365; Fax.: -

Diterima: 4 April 2020; Direvisi: 27 April 2020 ; Disetujui: 28 April 2020

DOI: 10.25299/saintis.2020.vol20(01).4779
\end{abstract}

\section{Abstrak}

Penelitian ini bertujuan untuk mengidentifikasi rencana teknopolitan di Kabupaten Pelalawan, mengidentifikasi implementasi rencana teknopolitan di Kabupaten Pelalawan dan merumuskan strategi pengembangan teknopolitan di Kabupaten Pelalawan. Metode penelitian yang digunakan deduktif kualitatif dengan pendekatan deskriptif. Metode pengumpulan data dengan observasi, telaah pustaka dan wawancara. Adapun pemilihan responden yang diwawancara adalah dengan cara purposif sampling. Setelah melakukan penelitian, didapat kesimpulan bahwa dalam masterplan Teknopolitan Pelalawan direncanakan akan dikembangkan menjadi 7 zona, yakni zona pendidikan, zona riset, zona industri, zona perumahan, zona sarana dan pelayanan umum, zona perdagangan dan jasa, dan zona lindung dan konservasi. Pengembangan kawasan teknopolitan yang terdiri dari 7 zona telah memasuki tahap awal perkembangan dimana pada tahapan ini telah dibangun kawasan pendidikan berupa sekolah tinggi teknologi pelalawan (ST2P) dan lembaga riset yang meneliti bibit kelapa sawit dan klinik kelapa sawit (PPKS). Sementara progres lainnya adalah mulai dibangunnya sarana prasarana seperti jalan menuju dan dalam kawasan teknopolitan yang telah dibuka dan diperkeras. Untuk zona lindung dan konservasi juga telah disiapkan bibit untuk pembangunan kebun raya. Sedangkan untuk zona lainnya masih dalam tahap perencanaan. Adapun strategi dalam pengembangan teknopolitan selanjutnya adalah memaksimalkan kinerja ST2P sebagai pusat inovasi yang nantinya menginkubasi perusahaan pemula dalam industri hilir kelapa sawit dan memberikan layanan bisnis dan teknologi kepada UMKM yang sudah ada.

Kata Kunci: Teknopolitan, Inovasi, Teknologi

\begin{abstract}
This study aims to identify techno park plans in Pelalawan Regency, identifying the implementation of the techno park plan in Pelalawan Regency and formulation techno park development strategy in Pelalawan Regency. The research method used is qualitative deductive with a descriptive approach. Data collection methods by observation, study of literature and interviews. The selection of respondents interviewed was by purposive sampling. After conducting the research, it was concluded that the Pelalawan Techno park masterplan was planned to be developed into 7 zones, namely the education zone, the research zone, the industrial zone, the housing zone, the public service and service zone, the trade and service zone, and the protection and conservation zone. The development of techno park areas consisting of 7 zones has entered an early stage of development. In this early stage, an educational building has been established, namely Sekolah Tinggi Teknologi Pelalawan (ST2P) and also was established research institute, namely Pusat Penelitian Kelapa Sawit (PPKS). While other progress has begun to be the construction of infrastructure facilities such as roads leading to and within techno park areas that have been opened and hardened. For protection and conservation zones, seedlings have been prepared for the construction of botanical gardens. Whereas the other zones are still in the planning stage. The next strategy in technology development is to maximize the performance of ST2P as an innovation center that will incubate startup companies in the downstream palm oil industry and provide business and technology services to existing UMKM.
\end{abstract}

Keywords: Techno Park, Inovation, Technology

\section{PENDAHULUAN}

Teknologi dan inovasi menjadi faktor utama sebagai stimulus pertumbuhan dan pengembangan ekonomi. Pembangunan suatu wilayah yang berorientasi pada peningkatan teknologi dan inovasi akan membawa suatu wilayah menjadi wilayah yang maju dan berdaya saing tinggi. Tentu hal ini tidak terlepas dari peran universitas sebagai pusat inovasi dan teknologi. Maka peran universitas menjadi sangat krusial dalam menentukan kemajuan suatu wilayah. Namun yang menjadi permasalahan adalah rendahnya tingkat inovasi yang diberikan universitas. Umumnya hasil penelitian yang diadakan universitas terbatas hanya sampai publikasi tanpa ada tindak lanjut untuk menjadi suatu produk yang dikomersilkan oleh industri [1].

Salah satu strategi untuk menghubungkan antara universitas dengan dunia industri adalah melalui konsep teknopolitan. Melalui teknopolitan, universitas menjadi pusat inovasi yang terintegrasi dengan kegiatan produktif (industri) dalam suatu 
kawasan yang saling terhubung. Kerjasama ini tentunya akan meningkatkan nilai tambah dan daya saing produk unggulan di suatu wilayah [2].

Kebijakan teknopolitan di Indonesia telah tertuang dalam Rencana Pembangunan Jangka Menengah Nasional (RPJMN) 2015-2019, dimana pemerintah menetapkan 100 Science and Technopark (STP) yang tersebar di Indonesia untuk dikembangkan. Dari 100 Science and Technopark yang dikembangkan, kawasan teknopolitan Pelalawan merupakan salah satunya [3].

Kabupaten Pelalawan merencanakan pembangunan kawasan teknopolitan dengan berbasis pada industri hilir kelapa sawit. Hal ini sejalan dengan Master plan Percepatan dan Perluasan Pembangunan Ekonomi Indonesia (MP3EI) 2011-2025, terutama pengembangan Koridor Ekonomi Pulau Sumatera, yang menjadikan kelapa sawit, karet dan batu bara sebagai sektor unggulan. Pengembangan teknopolitan Pelalawan yang fokus terhadap industri hilir kelapa sawit, merupakan langkah strategis untuk mengembangkan potensi sumber daya alam di Provinsi Riau. Dengan adanya teknopolitan Pelalawan, akan meningkatkan nilai tambah bagi pengembangan sektor unggulan berbasis teknologi dan inovasi di Riau pada umumnya, dan di Kabupaten Pelalawan pada khususnya [4].

Tidak hanya kerjasama antara universitas dan dunia industri, peranan pemerintah sangat dibutuhkan dalam pengembangan kawasan teknopolitan. Keberhasilan teknopolitan Pelalawan tentunya akan sangat terkait dengan kontribusi yang diberikan pemerintah Kabupaten Pelalawan dalam mengembangkan kawasan teknopolitan. Peranan pemerintah terkait dengan penyediaan lahan dan sarana prasarana dalam kawasan teknopolitan. Dalam penelitian Meiningrum, ditemukan bahwa belum memadainya akses jalan dan sarana prasarana yang ada di kawasan teknopolitan Pelalawan, serta adanya kendala dalam pembebasan lahan. Selain itu, pembiayaan teknopolitan juga menjadi suatu kendala. Untuk membangun teknopolitan Pelalawan dengan luas kawasan mencapai 4840 Ha tentunya membutuhkan anggaran yang besar [5].

Dari permasalahan yang sudah dijabarkan diatas, maka timbullah pertanyaan apakah implementasi kawasan teknopolitan ini telah berjalan dengan baik atau tidak. Untuk itu, peneliti tertarik untuk melakukan penelitian tentang analisis implementasi kawasan teknopolitan di Kabupaten Pelalawan.

\section{Tujuan Penelitian}

Penelitian ini bertujuan: 1. Mengidentifikasi rencana teknopolitan di Kabupaten Pelalawan; 2. Mengidentifikasi implementasi rencana teknopolitan di Kabupaten Pelalawan; 3.
Merumuskan strategi pengembangan teknopolitan di Kabupaten Pelalawan.

\section{Ruang Lingkup Wilayah}

Lokasi kegiatan ini secara makro adalah wilayah administrasi Kabupaten Pelalawan dan sekitarnya, sedangkan secara mikro adalah kawasan yang akan ditetapkan sebagai Kawasan Teknopolitan seluas kurang lebih 4840 hektar.

\section{METODOLOGI}

Metode yang digunakan dalam penelitian ini adalah metode deduktif kualitatif. Adapun pendekatan yang digunakan dalam penelitian ini adalah pendekatan deskriptif, yaitu dengan menceritakan tentang fenomena yang ada. Adapun tahapan penelitian ini adalah:

1. Menemukan isu permasalahan

Isu permasalahan dalam penelitian ini adalah rendahnya tingkat inovasi yang diberikan universitas. Hasil penelitian yang diadakan universitas terbatas hanya sampai publikasi tanpa ada tindak lanjut untuk menjadi suatu produk yang dikomersilkan oleh industri. Permasalahan ini bisa dijawab dengan konsep teknopolitan.

2. Mengkaji teori

Mengemukakan teori-teori yang relevan dengan teknopolitan, mulai dari sejarah teknopolitan, kebijakan dan perkembangan teknopolitan. Pengkajian teori ini menghasilkan pengertian dan pemahaman mengenai permasalahan yang dicari jawabnya melalui penelitian.

3. Merumuskan tujuan penelitian

Melihat studi kasus teknopolitan Pelalawan, mulai dari tahap perencanaan, perkembangan implementasi teknopolitan hingga solusi strategi pengembangan teknopolitan Pelalawan selanjutnya.

4. Mengumpulkan data

Metode pengumpulan data adalah dengan observasi, telaah pustaka dan wawancara. Observasi dilakukan melalui pengamatan langsung di lapangan untuk mengetahui dan mengamati keadaan di kawasan teknopolitan. Telaah pustaka dilakukan dengan cara mengumpulkan data dan informasi dengan cara membaca atau mengambil literatur laporan, jurnal, artikel, bahan seminar, bahan perkuliahan, dan sumber-sumber lainnya yang ada kaitannya dengan kawasan teknopolitan. Adapun wawancara dilakukan untuk mendapatkan informasi tambahan tentang teknopolitan Pelalawan. Wawancara dilakukan dengan narasumber yang terkait dalam perencanaan dan implementasi kawasan teknopolitan Pelalawan. Pada penelitian ini, yang menjadi narasumber adalah BAPEDDA Kabupaten Pelalawan, PU Kabupaten Pelalawan, 
dan Pemerintah Kecamatan Langgam. Pemilihan responden yang diwawancara adalah dengan cara purposif sampling.

5. Menganalisis data

Teknis analisis yang digunakan adalah teknis analisis deskriptif. Analisis data dilakukan dengan mencari dan mengatur secara sistematis hasil wawancara, hasil observasi, dan telaah pustaka. Kegiatan analisis dilakukan dengan menelaah data, menata, membagi menjadi satuan-satuan yang dapat dikelola, mensintesis, mencari pola, menemukan apa yang bermakna.

6. Menarik kesimpulan

Menarik kesimpulan tentang rencana teknopolitan Pelalawan, mendeskripsikan perkembangan teknopolitan Pelalawan, mengembangkan strategi pengembangan terkait temuan gambaran dan permasalahan dalam implementasi teknopolitan Pelalawan.

\section{HASIL DAN DISKUSI}

Kawasan Teknopolitan terletak di Kecamatan Langgam, Kabupaten Pelalawan. Berjarak 60 Km dari Kota Pekanbaru, ibukota Provinsi Riau. Kawasan Teknopolitan juga berdekatan dengan aliran Sungai Kampar, yang muaranya akan dijadikan pelabuhan yang letaknya berdekatan dengan dengan Selat Melaka.
Kawasan Teknopolitan ini dikembangkan pada lahan seluas 4840 Ha. Kawasan Teknopolitan di Kabupaten Pelalawan ini merupakan teknopolitan terluas di Indonesia.

\section{Identifikasi Rencana Teknopolitan}

Kawasan Teknopolitan Pelalawan ditetapkan dengan visi, yakni "Menjadi kawasan utama Pelalawan bagi pemajuan dan pemanfaatan iptek dan inovasi berkelas dunia yang ramah lingkungan Tahun 2033".

Berdasarkan kepada visi Kawasan Teknopolitan Pelalawan, selanjutnya misi pembangunan Kawasan Teknopolitan Pelalawan dirumuskan sebagai berikut: 1.Mengembangkan SDM berkualitas; 2.Mendorong pengembangan budaya kreatif inovatif masyarakat daerah; 3.Mengembangkan pusat-pusat keunggulan untuk mendorong pemajuan dan pemanfaatan iptek dan inovasi; 4.Menumbuhkembangkan bisnis-bisnis inovatif; 5.Mendukung pengembangan keunggulan (daya saing) khas daerah; 6.Memberikan pelayanan berbasis iptek; dan 7.Mengelola pembangunan hijau (greendevelopment) di kawasan.

Pengembangan kawasan teknopolitan terdiri dari 7 zona yakni zona pendidikan, zona riset, zona industri, zona perumahan, zona sarana dan pelayanan umum, zona perdagangan dan jasa, dan zona lindung dan konservasi (Tabel 1)[6].

Tabel 1. Arahan Pemanfaatan Lahan di Tiap Zona pada Kawasan Teknopolitan Pelalawan

\begin{tabular}{|c|c|}
\hline Zona & Arahan Pemanfaatan Lahan \\
\hline $\begin{array}{l}\text { Zona 1: } \\
\text { Pendidikan } \\
\text { Luas: } 100 \mathrm{Ha}\end{array}$ & $\begin{array}{l}\text { Arahan: } \\
\text { 1. Universitas / Perguruan Tinggi, } \\
\text { 2. Sekolah Kepolisian } \\
\text { 3. TK \& SD } \\
\text { 4. SMP \& SMA } \\
\text { 5. Akademi Komunitas } \\
\text { 6. Area Perkemahan }\end{array}$ \\
\hline $\begin{array}{l}\text { Zona } 2 \text { : } \\
\text { R\&D (Riset dan Pengembangan) } \\
\text { Luas: } 180 \mathrm{Ha}\end{array}$ & $\begin{array}{l}\text { Arahan: } \\
\text { 1. Perkantoran dan pusat penelitian Kelapa Sawit, } \\
\text { 2. Lembaga Litbang } \\
\text { 3. Perkantoran Pusat Inovasi } \\
\text { 4. Laboratorium peternakan } \\
\text { 5. Cadangan untuk lahan pengembangan Pusat Inovasi dan Fasilitas Riset } \\
\text { lainnya }\end{array}$ \\
\hline $\begin{array}{l}\text { Zona 3: } \\
\text { Industri } \\
\text { Luas: } 818 \mathrm{Ha}\end{array}$ & $\begin{array}{l}\text { Arahan: } \\
\text { 1. Industri oleo pangan } \\
\text { 2. Industri oleo kimia dasar } \\
\text { 3. Industri oleo kimia turunan } \\
\text { 4. Industri kecil dan menengah (IKM) } \\
\text { 5. Aneka Industri (aneka pengolahan pangan yang menghasilkan kebutuhan } \\
\text { pokok di bidang pangan seperti garam, gula, margarine, minyak goreng, } \\
\text { shampo, kosmetik, dan lain lain }\end{array}$ \\
\hline $\begin{array}{l}\text { Zona } 4: \\
\text { Perumahan } \\
\text { Luas: } 502 \mathrm{Ha}\end{array}$ & $\begin{array}{ll}\text { Arahan: } \\
\text { 1. Besar } \\
\text { 2. Kecil } \\
\text { 3. } & \text { Sedang } \\
\end{array}$ \\
\hline $\begin{array}{l}\text { Zona } 5 \text { : } \\
\text { Sarana dan Pelayanan Umum } \\
\text { Luas: } 160 \mathrm{Ha}\end{array}$ & $\begin{array}{l}\text { Arahan: } \\
\text { 1. sarana pelayanan umum transportasi, } \\
\text { 2. sarana pelayanan umum kesehatan, } \\
\text { 3. sarana pelayanan umum olahraga (Gedung Olahraga, Gym dan lain lain), } \\
\text { 4. sarana pelayanan umum sosial budaya, dan sarana pelayanan umum } \\
\text { peribadatan }\end{array}$ \\
\hline
\end{tabular}




\begin{tabular}{|c|c|}
\hline Zona & Arahan Pemanfaatan Lahan \\
\hline $\begin{array}{l}\text { Zona } 6 \text { : } \\
\text { Perdagangan dan Jasa } \\
\text { Luas: } 282 \mathrm{Ha}\end{array}$ & $\begin{array}{l}\text { Arahan: } \\
\text { 1. perdagangan jasa deret dan perdagangan jasa tunggal, (bila diperlukan } \\
\text { dapat dirinci lebih lanjut ke dalam lokasi PKL, pasar tradisional, pasar } \\
\text { modern, pusat perbelanjaan, dan sebagainya), } \\
\text { 2. kantor pemerintah dan swasta yang merupakan bagian dari jasa, } \\
\text { 3. bangunan penginapan (Hotel, guest house, dll), } \\
\text { 4. bangunan tempat pertemuan (Aula, tempat konferensi), } \\
\text { 5. bangunan pariwisata/rekreasi di ruang tertutup (bioskop, area bermain), } \\
\text { dan lain lain. }\end{array}$ \\
\hline $\begin{array}{l}\text { Zona } 7 \text { : } \\
\text { Lindung dan Konservasi } \\
\text { Luas: } 2228 \mathrm{Ha}\end{array}$ & $\begin{array}{l}\text { Arahan: } \\
\text { 1. fungsi konservasi, } \\
\text { 2. fungsi kebun percontohan/riset, } \\
\text { 3. fungsi lindung. Pemanfaatan }\end{array}$ \\
\hline
\end{tabular}

Sumber : Peraturan Zonasi Investment Guidelines Kawasan Techno Park Pelalawan, 2015 [6]

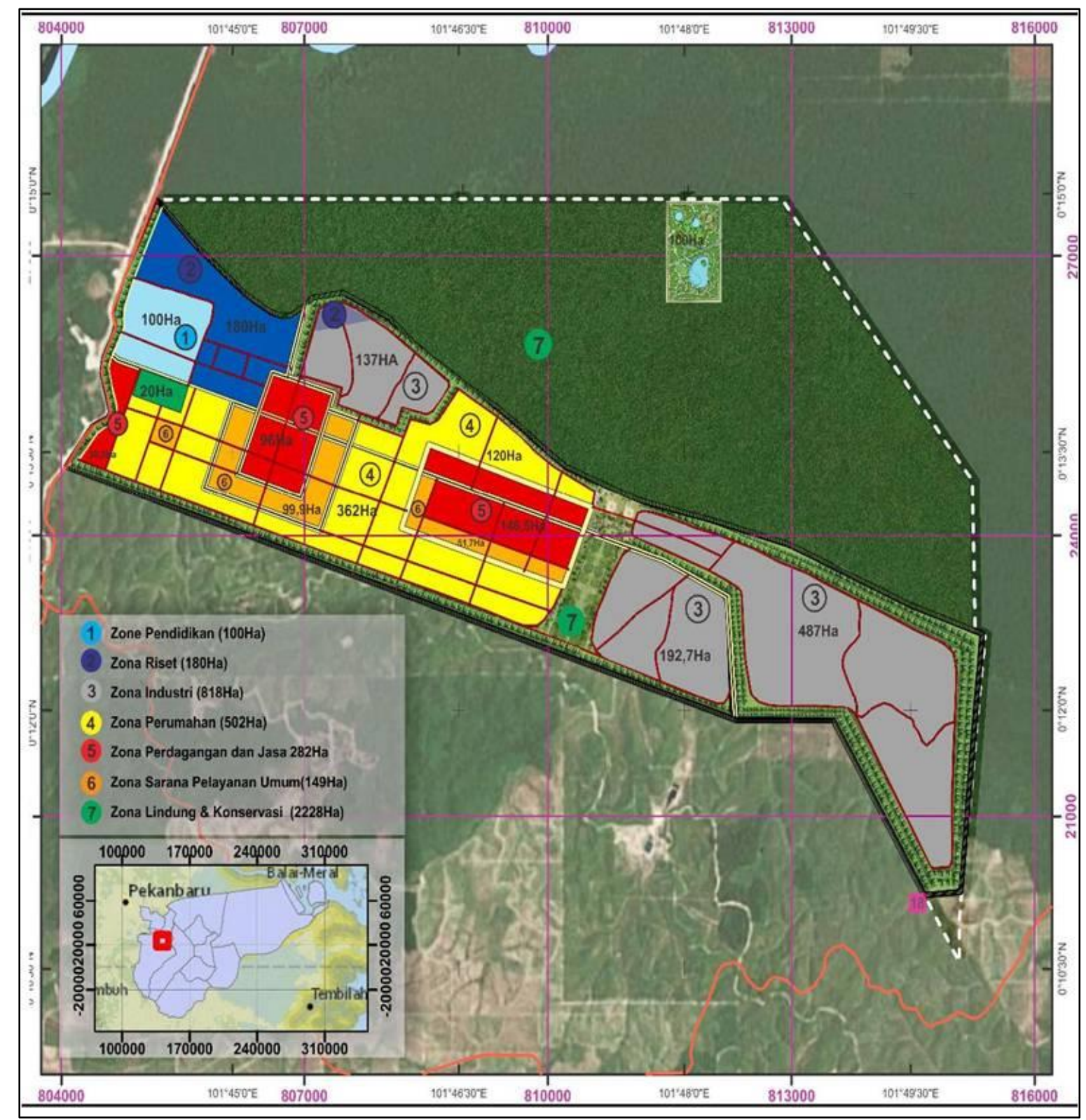

Gambar 1. Peta Pembagian Zona di Kawasan Teknopolitan

Sumber : Masterplan Kawasan Techno Park Pelalawan, 2015 [1] 


\section{Identifikasi Implementasi Rencana Teknopolitan}

Saat ini fokus utama pengembangan teknopolitan terjadi pada zona pendidikan dan zona riset. Zona industri masih dalam tahap pembukaan lahan. Pada zona sarana pelayanan umum fokus pada pembangunan jalan menuju dan dalam kawasan. Zona lindung dan konservasi sedang dalam tahap persiapan bibit. Sedangkan zona perumahan serta zona perdagangan dan jasa belum ada langkah pengerjaan.

\section{Zona Pendidikan}

Pada saat ini telah ada Sekolah Tinggi Teknologi Pelalawan (ST2P) yang difungsikan sebagai kampus ST2P, pusat inovasi, dan kantor pusat pengelolaan kawasan. Operasional perguruan tinggi ini menggunakan dana hibah yang sudah tercantum didalam APBD Kabupaten Pelalawan sebesar Rp. 4,3 Miliar rupiah. Pembangunan kawasan pendidikan ini baru rampung pada tahun 2016 dan beroperasi pada tahun 2017. Akademisi memainkan peran penting dalam teknopolitan dimana akademisi sebagai penggerak pendidikan, pengetahuan baru dan menciptakan tenaga kerja terlatih secara terus menerus yang nantinya dapat menciptakan inovasi baru.

Kampus ST2P ini dikelolah oleh Yayasan Amanah yang bekerjasama dengan pemerintah dan unit pelayanan teknis dalam mengelola pengembangan dan kegiatan belajar mengajar beserta riset. Saat ini perguruan tinggi ini terdiri dari 2 program studi yakni agroteknologi dan teknik industri, Dimana saat ini tersedia 12 dosen tetap, 6 dosen luar biasa, 3 dosen tamu, dan 2 dosen keahlian khusus kajian islam yang membantu dalam belajar mengajar [7].

Pada tahun 2017 mahasiswa dan mahasiswi yang terdaftar di ST2P ini berjumlah 33 orang dan pada tahun 2018 jumlah mahasiswa dan mahasiswi yang terdaftar berjumlah 70 orang. Kampus ST2P saat ini beroperasi dengan menggunakan biaya dari pemerintah Kabupaten Pelalawan di bantuan dari CSR perusahaan melalui beasiswa ST2P.

Perguruan tinggi yang didirikan berperan penting didalam pengembangan sumber daya alam yang ada pada kawasana teknopolitan, dimana lembaga ini menciptakan dan menghasilkan berbagai investasi dan inovasi dengan memanfaatkan sumber daya alam. Selain itu lembaga ini merupakan berbasis penelitian dan pengembangan usaha dimana dilakukan penelitian terhadap sumber daya alam unggulan agar dapat dimanfaatkan secara berkelanjutan sehingga dapat menyediakan bahan tanaman unggulan bagi para petani dan dapat mencetak kerja yang terampil dalam bidangnya.

Pada kampus ST2P ini telah beroperasi pusat inovasi yang berfungsi sebagai inkubator bisnis berbasis teknologi, dimana saat ini telah dilakukan seleksi tenant inkubator dan sedang menginkubasi 5 calon perusahaan pemula yang berbasis teknologi dengan bisnis yang tekait pengelolaan kelapa sawit dengan mengunakan teknologi modern.

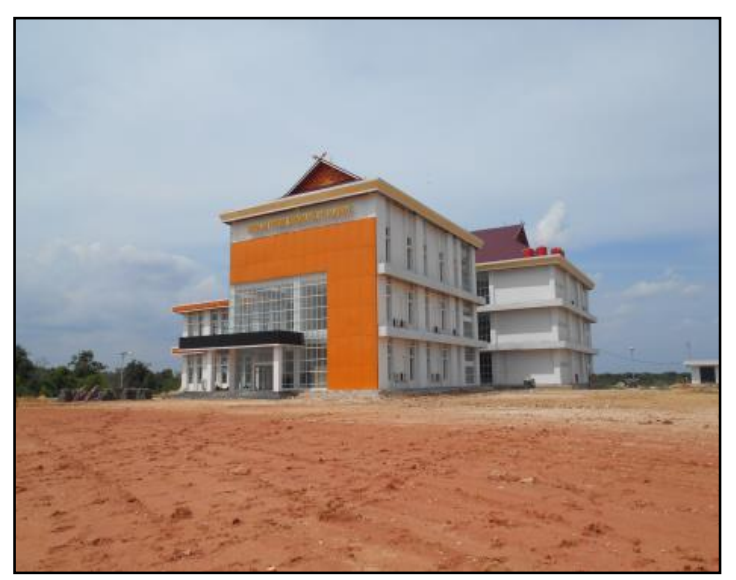

Gambar 2. Sekolah Tinggi Teknologi Pelalawan (ST2P)

\section{Zona Riset}

Pada kawasan teknopolitan terdapat lembaga riset terletak pada area ST2P dan saat ini mulai beroperasi dengan dibantu oleh Pusat Penelitian Kelapa Sawit (PPKS) Medan. Mahasiswa dan mahasiswi mengembangkan inovasi dibantu oleh PPKS Medan dalam pembangunan kebun bibit kelapa sawit dam klinik kelapa sawit yang saat ini baru terbangun pada lahan seluas $5 \mathrm{Ha}$ dari luas kawasan yang direncanakan sebesar $50 \mathrm{Ha}$. [7]. Nantinya bibit -bibit kelapa sawit yang telah di teliti dapat di salurkan kepada petani sawit yang ada pada kawasan teknopolitan menjadi bibit unggulan sehingga sawit memiliki buah yang lebih bagus dan masa panen yang lebih singkat.

Karakteristik petani swadaya yang saat ini perlu ditangani antara lain tingkat produktifitas yang rendah, belum memiliki teknik budidaya sawit yang baik, modal usaha yang minim. Dengan adanya lembaga riset, para petani diajarkaan bagaimana pembibitan dan budidaya kelapa sawit yang baik. Pemerintah dan PPKS Medan sepakat untuk bekerjasama dalam upaya pemberdayaan masyarakat dan revitalisasi kelapa sawit dimana kelapa sawit yang sudah tidak produktif digantikan dengan bibit unggul yang lebih baik.

Lembaga riset melalui sosialisasi dan seminar dengan para petani mengimpun para petani kelapa sawit dalam koperasi. Pengelolaan kelapa sawit perorangan akan dipindahkan menjadi manajemen koperasi sehingga lebih mudah dan efektif dalam penerapan praktek budidaya kelapa sawit yang baik. Keuntungan dari koperasi ini dapat merangkul para petani yang tadinya pekerja saja tapi juga menjadi pemilik lahan dan bisa menjadi lebih mandiri dan dapat memasarkan hasil perkebunannya sendiri. 


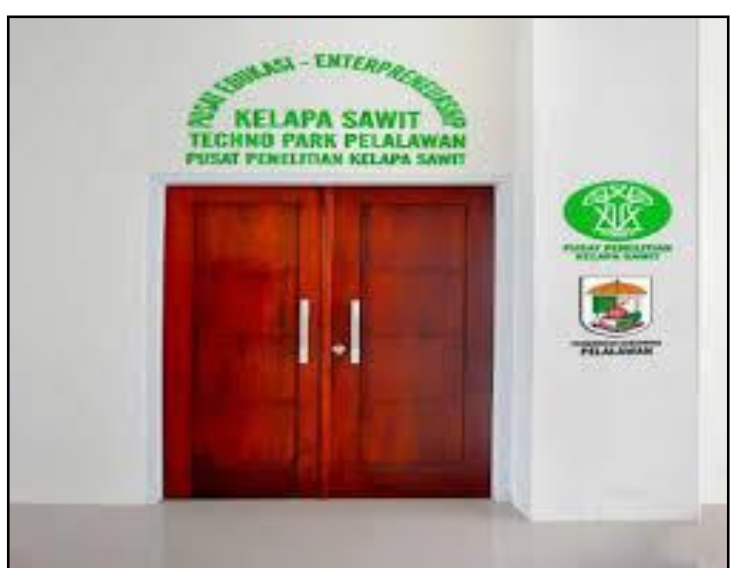

Gambar 3. Pusat Penelitian Kelapa Sawit (PPKS)

\section{Zona Industri}

Pengembangan zona industri saat ini masih dalam tahap pembukaan lahan. Seiring dengan pembukaan lahan, juga sedang dipersiapkan pembangunan pabrik kelapa sawit (PKS), pabrik bioplastik, pabrik pellet untuk bahan bakar power plan listrik. Pengembangan pabrik-pabrik ini akan dibantu oleh perusahaan-perusahaan yang bekerjasama dengan pemerintah Kabupaten Pelalawan. Perusahaan-perusahaan yang bekerjasama antara yakni PT. Rekayasa Engineering, PT. Pindad (PERSERO), Dewan Minyak Sawit Indonesia (DMSI) dan PPKS Medan.

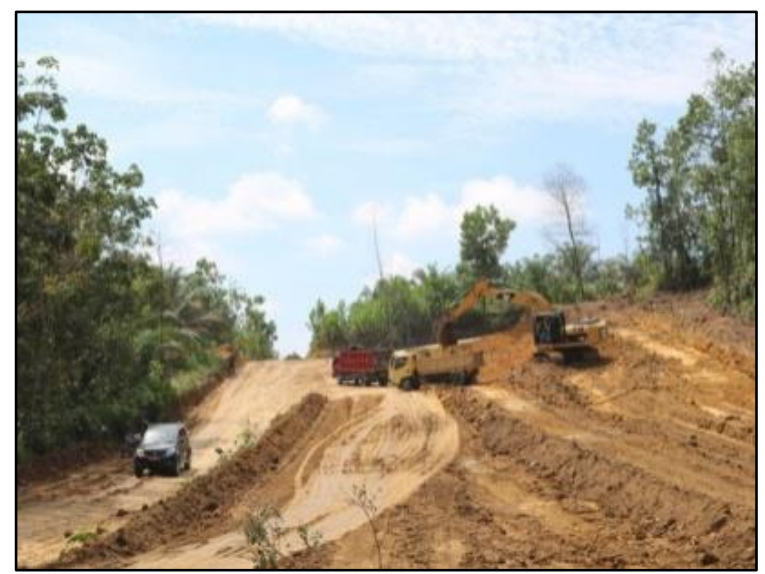

Gambar 4. Pembukaan Lahan Zona Industri

\section{Zona Sarana Pelayanan Umum}

Fasitas umum yang diadakan adalah peningkatan jalan menuju kawasan dan pembukaan serta pembangunan jalan di dalam kawasan. Diluar kawasan teknopolitan, juga telah dibangun Pembangkit Listrik Tenaga Mesin Gas (PLTMG) dengan kapasitas 50 MW untuk tahap 1. Nantinya akan terus ditingkatkan kapasitasnya. Selanjutnya akan dibangun jaringan listrik dari PLTMG ke kawasan teknopolitan.

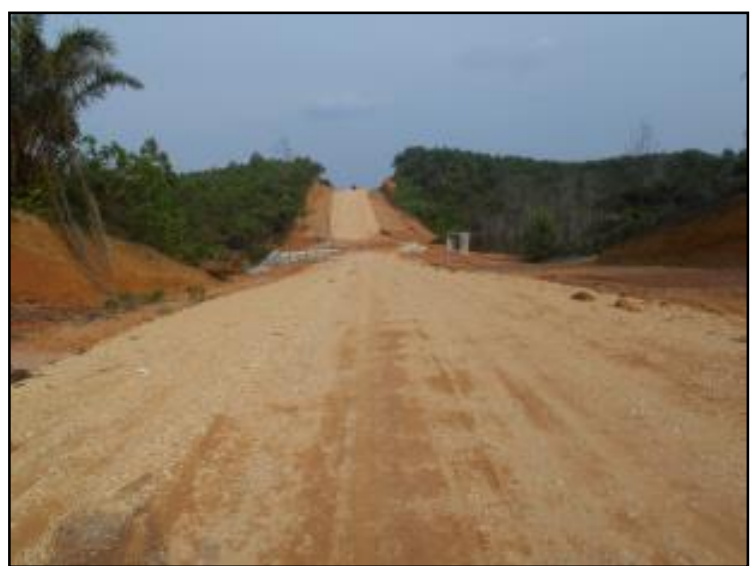

Gambar 5. Jalan dalam Kawasan Teknopolitan

\section{Zona Lindung dan Konservasi}

Pemerintah kabupaten pelalawan bekerjasama dengan Lembaga Ilmu Pengetahuan Indonesia (LIPI) mulai membangun kebun raya daerah pelalawan. Saat ini sedang dilakukan penyiapan bibit untuk kebutuhan kebun raya.

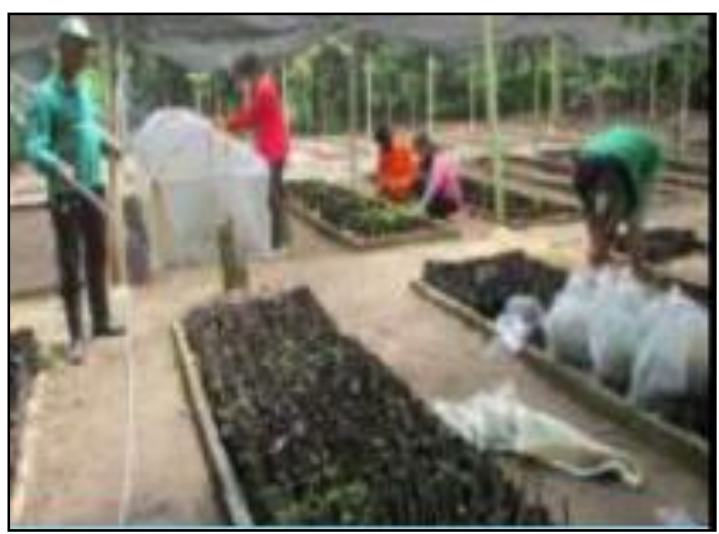

Gambar 6. Persiapan Bibit Untuk Zona Lindung dan Konservasi

\section{Strategi Pengembangan Kawasan Teknopolitan}

Salah satu indikator keberhasilan dalam pengembangan kawasan Teknopolitan adalah lahirnya perusahaan pemula berbasis teknologi dan peningkatan dalam layanan bisnis kepada UMKM yang sudah ada [1].

Tahap awal dalam pengembangan kawasan teknopolitan Pelalawan adalah pengembangan pada zona riset dan zona pendidikan. Pengembangan pada zona riset dan zona pendidikan ini akan terkait dengan aktifitas penelitian, inkubasi, dan pengembangan bisnis dengan target penciptaan perusahaan pemula dan pelayanan UMKM. Untuk itu, dalam pengembangan teknopolitan tahap awal ini, dibutuhkan peranan Pusat Inovasi yang melakukan aktifitas inkubasi bisnis dan pengembangan bisnis [1]. 
Ada beberapa tahapan inovasi yang mesti dilalui untuk mewujudkan suatu teknopolitan. Berikut tahapan inovasi (innovation readiness level) yang mesti dilalui untuk mewujudkan suatu inovasi yang utuh, dan berkelanjutan [8].

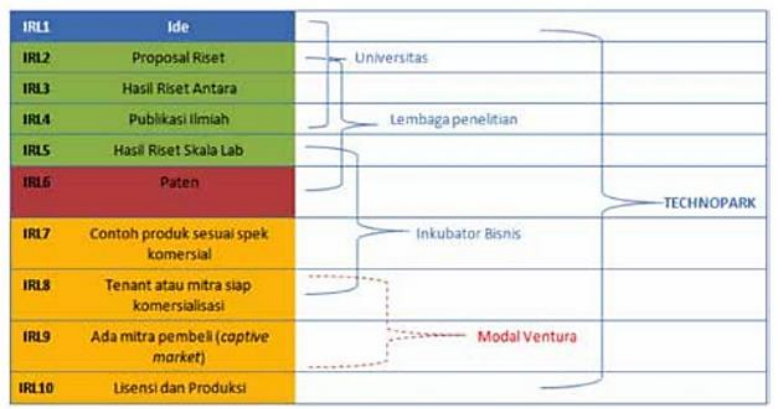

Gambar 7. Innovation Readiness Level (Tahapan Inovasi) [8].

Kampus ST2P dan lembaga riset PPKS mesti memaksimalkan perannya sebagai pusat inovasi yang nantinya menginkubasi perusahaan pemula dalam industri hilir kelapa sawit dan memberikan layanan bisnis dan teknologi kepada UMKM yang sudah ada.

Berperan sebagai pusat inovasi, ST2P dan PPKS tentunya akan menjadi sebuah Inkubator Bisnis. Untuk menunjang keberhasilan suatu inkubator bisnis, maka ST2P dan PPKS mesti memberikan pelayanan dengan menggunakan konsep 7S, yaitu: 1) Space, yaitu penyediaan ruang untuk kegiatan usaha tenant; 2) Shared office fasilities, yaitu penyediaan sarana perkantoran yang bisa dipakai bersama. Misalnya sarana fax, telepon, foto copy, ruang rapat, komputer, dan sekertaris; 3) Service, yaitu melakukan bimbingan dan konsultasi manajemen: marketing, finance, production, technology, dan sebagainya; 4) Support, yaitu memberikan bantuan dukungan penelitian dan pengembangan usaha dan akses penggunaan teknologi; 5) Skill Development, yaitu meningkatkan kemampuan SDM tenant melalui pelatihan, penyusunan rencana usaha, pelatihan manajemen, dan sebagainya; 6) Seed capital, yaitu penyediaan dana awal usaha serta upaya memeroleh akses permodalan kepada lembaga-lembaga keuangan; dan 7) Sinergy, yaitu penciptaan jaringan usaha baik antar usaha lokal maupun internasional [9][10][11]. Melihat dari konsep 7S ini, maka perlu dibangun badan usaha di bawah ST2P yang khusus menangani kegiatan inkubator bisnis [12][13]. Diharapkan dengan dibangunannya badan usaha dibawah ST2P, maka menejemen pengelolaan inkubator bisnis menjadi efisien dan profesional sehingga mampu melahirkan perusahaan tenant yang nantinya mengggerakkan roda perekomonian di Teknopolitan Pelalawan.

Selain itu mesti terjalin kerjasama yang berkualitas antara pihak pemerintah, akademisi dan pengusaha sebagai struktur dari kelembagaan
Teknopolitan. Setiap pihak memiliki peran masingmasing. Pemerintah bertanggung jawab dalam perizinan, penyediaan lahan dan penyediaan infrastruktur kawasan. Akademisi bertanggung jawab atas pengembangan inovasi dan teknologi. Pengusaha bertanggung jawab atas pemanfaatan dan pengolahan sumber daya yang ada[14][15]. Kolaborasi antara pihak pemerintah, akademisi dan pengusaha ini dikenal dengan konsep the triple helix [15].

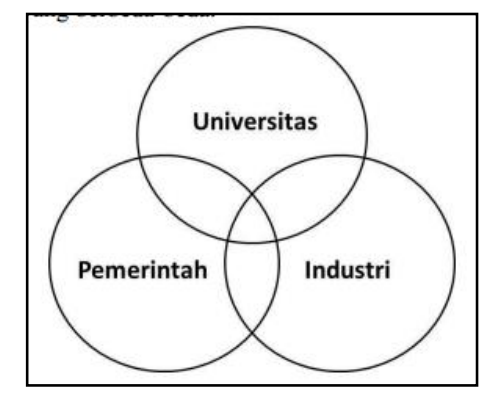

Gambar 8. The Triple Helix [15].

\section{KESIMPULAN}

Dalam master plan Teknopolitan Pelalawan direncanakan akan dikembangkan menjadi 7 zona, yakni zona pendidikan, zona riset, zona industri, zona perumahan, zona sarana dan pelayanan umum, zona perdagangan dan jasa, dan zona lindung dan konservasi. Pengembangan kawasan teknopolitan yang terdiri dari 7 zona telah memasuki tahap awal perkembangan dimana pada tahapan ini telah dibangun kawasan pendidikan berupa Sekolah Tinggi Teknologi Pelalawan (ST2P) dan lembaga riset yang meneliti bibit kelapa sawit dan klinik kelapa sawit (PPKS). Sementara progres lainnya adalah mulai dibangunnya sarana prasarana seperti jalan menuju dan dalam kawasan teknopolitan yang telah dibuka dan diperkeras. Untuk zona lindung dan konservasi juga telah disiapkan bibit untuk pembangunan kebun raya. Sedangkan untuk zona lainnya masih dalam tahap perencanaan. Adapun strategi dalam pengembangan teknopolitan selanjutnya adalah memaksimalkan kinerja ST2P sebagai pusat inovasi yang nantinya menginkubasi perusahaan pemula dalam industri hilir kelapa sawit dan memberikan layanan bisnis kepada UMKM yang sudah ada.

\section{REFERENSI}

[1] BPPT, Masterplan Kawasan Techno Park Pelalawan. 2015.

[2] S. Miranti, "Peluang dan Tantangan Pengembangan Teknopolitan dalam Meningkatkan Daya Saing Indonesia," J. Pembang. Nagari, vol. 1, no. 2, pp. 37-52, 2016.

[3] N. Arifin Muhammad, M. Muhyiddin, A. Faisal, and I. Angger Anindito, "Studi Pembangunan Science and Technopark (STP) di Indonesia," J. Perenc. Pembang. Indones. J. Dev. Plan., vol. 1, 
no. 1, pp. 13-31, 2017, doi: 10.36574/jpp.v1i1.6.

[4] BPPT, Laporan Akhir Penyusunan Masterplan Teknopolitan Kabupaten Pelalawan. 2012.

[5] A. P. Meiningrum, "Kapasitas Pemerintah Kabupaten Pelalawan dalam Pembangunan Kawasan Teknopolitan (Studi Pembangunan Kawasan Pendidikan)," JOM FISIP, vol. 4, no. 1, pp. 1-15, 2017.

[6] BPPT, Peraturan Zonasi Investment Guidelines Kawasan Techno Park Pelalawan. 2015.

[7] Zardewan, "Science Techno Park Pelalawan sebagai Model Percontohan Pengembangan STP Berbasis Pertanian," 2018, pp. 20172018, [Online]. Available: http://drn.go.id/files/2018/SP 1 DRN/Sesi_B_3_Mr_Zardewan_Bahan_Bupati _pada_DRN_9_Agustus_2018-compressed.pdf.

[8] Tim Analis Kebijakan BAPPENAS, Studi Pengembangan Technopark di Indonesia: Survey terhadap 10 Embrio Technopark di Indonesia. 2015.

[9] R. Hasbullah, M. Surahman, A. Yani, D. P. Almada, and E. N. Faizaty, "Peran Inkubator Bisnis Perguruan Tinggi dalam Peningkatan Kinerja Usaha UKM Pangan (Role of Universty Bussiness Incubators on the Improvement of Food SMEs Bussiness Performances)," J. Ilmu Pertan. Indones., vol. 20, no. 1, pp. 59-65, 2015, [Online].

Available: journal.ipb.ac.id/index.php/JIPI.
[10] L. Aldianto, I. Raafaldini Mirzanti, D. Sushandoyo, and E. Fitriana Dewi, "Pengembangan Science Dan Technopark Dalam Menghadapi Era Industri 4.0 - Sebuah Studi Pustaka," J. Manaj. Indones., vol. 18, no. 1, pp. 68-76, 2018, doi: 10.25124/jmi.v18i1.1261.

[11] A. Nurasyiah, "Analisis Kinerja Inkubator Bisnis dalam Pendampingan Usaha Tenant (Studi Kasus Inkubator Bisnis Teknologi Solo Technopark)," Skripsi, 2017.

[12] Septiana Ayu Estri Mahani, "Tinjauan model inkubator bisnis rintisan (bisnis start up) di indonesia," J. Manaj. dan Bisnis, vol. 12, no. 1, pp. 76-95, 2015, doi: https://doi.org/10.29313/performa.v0i1.304 4.

[13] M. H. Wibowo, Konsep Pengelolaan, Fungsi, dan Aktivitas Science and Technology Park (STP): Perbandingan Beberapa STP dan Konsep Pengembangan IPB Science Techno Park. 2017, pp. 1-17.

[14] Warseno, "Model Pengelolaan Kawasan Teknopolitan," J. Ind. Eng. Manag. Syst., vol. 7, no. 1, pp. 69-80, 2014.

[15] M. B. Mukhlish, "Kolaborasi Antara Universitas, Industri dan Pemerintah Dalam Meningkatkan Inovasi dan Kesejahteraan Masyarakat: Konsep, Implementasi dan tantangan," J. Adm. Bisnis Terap., vol. 1, no. No.1, pp. 31-43, 2018. 